\title{
Social Responsibility vs. Political Advocacy
}

Elton N. Kaufmann, MRS President

Few here would deny that the individual citizen should bear a burden of social responsibility and enjoy the right of political advocacy. But what about the institution? In particular, what about the institution which is a nonprofit learned scientific society. Most would agree that the burden of social responsibility not only remains but is multiplied by the greater than individual impact such an organization may have on society. The right of political advocacy however, if anything, is diminished and restricted. Again, because of the greater potential impact of an institution on the political process. In what arena is it appropriate for MRS to espouse a cause on behalf of its collective membership and the greater materials research community and where must it (or should it) remain either scrupulously neutral or totally silent?

There are many gray areas here, but there are also some reasonably definitive and sensible guidelines. First, MRS is made up of individuals each of whom may, and does, express an opinion on any issue. If a sizable proportion of the materials community tends to hold a given view and

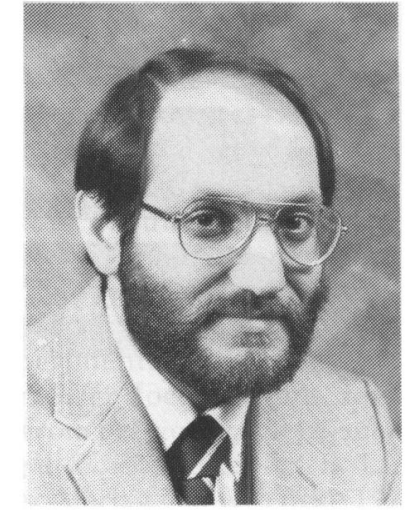

express it, then the Society will likely be viewed as holding that view in spite of the absence of an explicit and official endorsement.

This is natural and not necessarily bad. But, in general, the Society must neither promote nor endorse a viewpoint simply because it represents that of the majority of its members. In some cases it would clearly jeopardize the privileged nonprofit status we enjoy as a scientific and educational organization. But more significantly,

\section{Janis Quality! SuperTran Cryostat Systems}

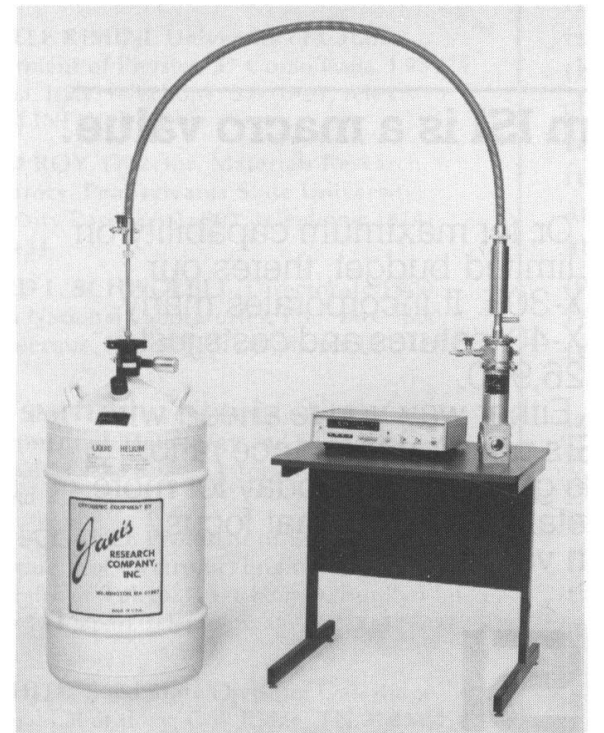

These versatile cryostats com-

bine a flexible transfer line with a cold finger sample mount and a variety of vacuum jackets.

They provide fast cooldown to $2 \mathrm{~K}$, and smoothly vary the temperature to $300 \mathrm{~K}(600 \mathrm{~K}$, optional) with excellent stability.

Complete systems are supplied with temperature sensors and automatic controllers, plus storage dewars and vacuum pumping stations.

Please contact us with your requirement. it would deter the materials researcher who holds the minority view from joining us. That is, it would add a criterion for selection of MRS, as the scientist's choice for a professional organization, which is not germane to the practice of materials research or the purpose of the Society.

When we consider many controversial issues of the day which are either completely unrelated or highly tangential to our professional pursuits, it is easy to conclude that MRS must abstain from positiontaking, whether or not a consensus sentiment of the membership is perceived. When the issues strongly influence our professional lives, what is the proper role of the Society? In this arena, the Society has two choices. It may again eschew association with a controversial subject so as not to chance offending one side or the other (or both). Or it may step forward and insert itself as a neutral arbiter, as ombudsman, or discussion facilitator so as to advance the controversy toward resolution for the benefit of all involved. It may also, through its forums, help distill from contentious issues the technical aspects about which the MRS constituency may be expert. This, I submit, is the more socially responsible path to follow.

These thoughts are not presented here in the abstract. They are prompted by the increasing contact MRS has been experiencing with controversial issues and with policy and funding organs of government The issues of large facilities versus smal science, of international competition and technological leadership, of technology export versus free exchange of information have all surfaced in our meetings or committees. As recognition of MRS and its members, as the single most broad-based and knowledgeable group of materials researchers in existence, has increased, we have been approached by many university, government, and private sector organizations with requests for help and advice. As a responsible member of the scientific community and the larger world community, our Society should offer its expertise to those who require it and its forums for the open discussion of technically relevant subjects, whether controversial or not.

There is a risk attendent to embracing responsible involvement while trying to walk the fine line of neutrality. The leaders of MRS should accept this challenge and the membership should encourage the bolder course through their participation. 


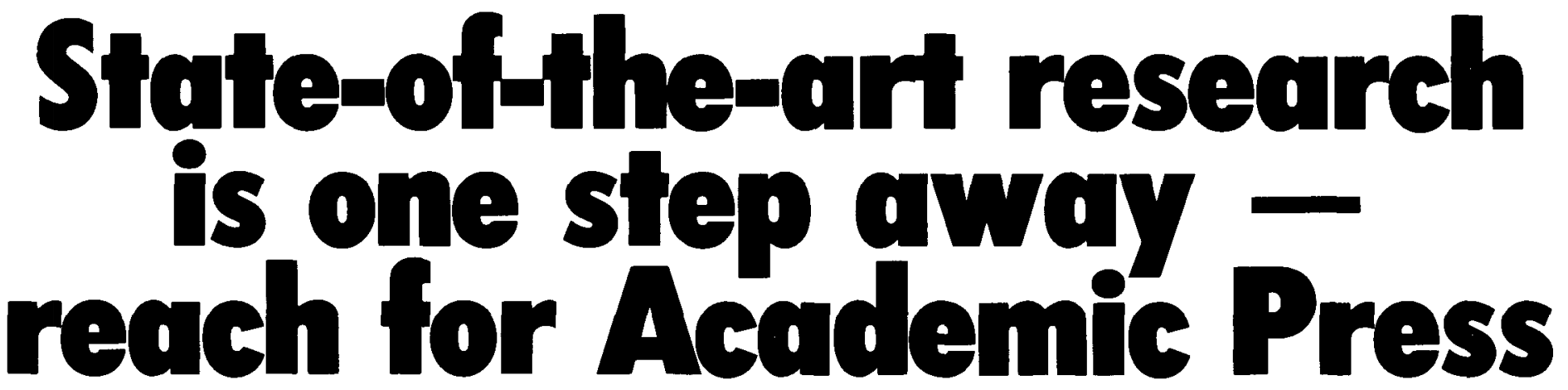

\section{Total Pressure Measurements in Vacuum Technology}

\section{A. Berman}

Vacuum technology: a critical aspect of many modern industries, from integrated circuits to plasma research. Now there is a comprehensive treatment of the basic concepts underlying vacuum pressure measurement. This volume presents detailed information on the general processes and problems involved in measurement techniques, as well as on the physical principles on which vacuun gauges operate. It also includes hard-to-find data on low total pressure and an up-to-date survey of current techniques and methods of measuring it. $\$ 59.50408$ pp. ISBN: 0-12-092440-4 1985

\section{Synthetic Modulated Structures}

\author{
Edited by \\ Leroy L. Chang \\ B.C. Giessen \\ A Volume in the
}

MATERIALS SCIENCE AND TECHNOLOGY Series

From the preface: This volume is intended primarily as a reference book for workers in the general area of modulated structures; however, it contains sufficient tutorial material to serve as an introduction as well. The chapters have been written with the intent of covering the major points with plentiful references, so that interested readers can have access to more extensive or specific treatments.

$\$ 87.00502$ pp. ISBN: 0-12-170470-X 1985

\section{Rates of Phase Transformations}

\section{R.H. Doremus}

The fundamentals of the kinetics of phase transformations are presented in this volume. The author integrates reviews of current knowledge with theory, experiments, and references to provide a clearly written introduction to this complex subject.

$\$ 29.00 \quad 192 \mathrm{pp}$

ISBN: 0-12-220530-8 October 1985

\section{Haindbook of Optical Constants of Solids}

\section{Edited by}

Edward D. Palik

A Volume in the

ACADEMIC PRESS HANDBOOK Series

The optical constants of a variety of materials metals, semiconductors, and insulators - have been collected in this unique reference. Experts in the field have reviewed and evaluated current literature on the optical properties of solids, and have compiled chapters that include:

- methods for the determination of the index of refraction $n$ and the extinction coefficient $k$ in various spectral regions;

- absorption mechanisms in solids;

- a single set of values of $n$ and $k$ for thirty-seven solids in the spectral range from $x$ rays to millimeter waves;

- detailed numerical tables and coarse graphs of data;

- original references.

\$110.00 804 pp. ISBN: 0-12-544420-6 1985

\section{Handbook of Glass Properties}

\author{
Narottam P. Bansal \\ R.H. Doremus \\ A Volume in the \\ ACADEMIC PRESS HANDBOOK \\ Series
}

This volume is a compilation of data on the properties of glasses. The authors have critically examined and correlated the most reliable data on the properties of multicomponent commercial silicate glasses, vitreous silica, and binary and ternary laboratory glasses.

in preparation c. $554 \mathrm{pp}$.

ISBN: 0-12-078140-9 April 1986

\section{Thin Films from Free Atoms and Particles}

\author{
Edited by
}

Kenneth J. Klabunde

From the preface: The coverage of this volume is as follows: First, an introduction to free atoms and particles is followed by a chapter describing the embryonic growth of films (dimers, trimers, and other small telomers formed and detected). Next, the current understanding of discharge processes for form ing free atoms and particles is reviewed, and then several chapters dealing with current technology, techniques, and materials follow.

in preparation (Cloth) c. $358 \mathrm{pp}$.

ISBN: 0-12.410755-9 December 1985

in preparation (Paper) c. $358 \mathrm{pp}$

ISBN: 0-12-410756-7 December 1985

\section{See these and other outstanding titles on Materials Science at the Academic Press exhibit...}

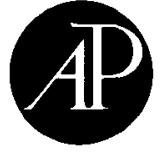

Academic Press, Inc.

Harcourt Brace Jovanovich, Publishers

Orlando, Florida 32887, U.S.A. - 24/28 Oval Road, London NW1 7DX, U.K

\begin{tabular}{|c|c|c|c|c|c|c|c|}
\hline Orlando & San Diego & New York & Austin & Londor & Toronto & Montreal & Sydney \\
\hline
\end{tabular}

